\title{
ESBL Producers in Gram Negative Isolates from Clinical Samples
}

\author{
Mita D. Wadekar* (D), J.V. Sathish, C. Pooja and S. Jayashree $\mathbb{D}$ \\ Department of Microbiology, Chamarajanagar Institute of Medical Sciences, Chamarajanagar - 571 111, \\ Karnataka, India.
}

\begin{abstract}
Resistance to beta lactam antibiotics is the most common cause for beta-lactamase production. Increasing number of extended spectrum beta-lactamase (ESBL) producers has reduced the treatment options which resulted in emergence of multidrug resistant strains, treatment failure and hence increased mortality. To detect phenotypically, ESBL producers in Gram negative isolates from different samples and to know their susceptibility pattern. A retrospective study of Gram negative isolates was conducted. Total of $\mathbf{5 2 1}$ isolates were isolated from various samples. They were processed and identified by standard procedures. The antibiotic susceptibility testing was performed by Kirby- Bauer disc diffusion method using CLSI guidelines. ESBL was detected by combination disk test. A total of 521 Gram negative isolates were isolated which included $E$. coli, Klebsiella pneumoniae, Citrobacter spp., Enterobacter spp., Proteus spp. and Acinetobacter spp. Pseudomonas aeruginosa. 0 f 521 isolates tested, ESBL was detected in $329(63.1 \%)$ isolates. These isolates showed maximum susceptibility to piperacillin- tazobactam (86\%) followed by imipenem (78.4\%), amikacin (63.5\%), cotrimoxazole (54.4\%), ciprofloxacin (51\%), amoxi-clav (44.9\%), cefepime (44.1\%), gentamicin (38.9\%), cefoxitin (34.9\%) and ampicillin (19.1\%). ESBL producers which are resistant to beta lactam antibiotics have become a major problem. Detection of these beta-lactamase enzymes by simple disk method and its reporting will help clinicians in prescribing proper antibiotics.
\end{abstract}

Keywords: Clinical samples, Gram negative isolates, ESBL, Antibiotic susceptibility

\footnotetext{
*Correspondence: drmdw20@gmail.com

(Received: April 12, 2020; accepted: September 17, 2020)

Citation: Wadekar MD, Sathish JV, Pooja C, Jayashree S. ESBL Producers in Gram Negative Isolates from Clinical Samples. J Pure Appl Microbiol. 2020;14(3):2027-2032. doi: 10.22207/JPAM.14.3.42

(C) The Author(s) 2020. Open Access. This article is distributed under the terms of the Creative Commons Attribution 4.0 International License which permits unrestricted use, sharing, distribution, and reproduction in any medium, provided you give appropriate credit to the original author(s) and the source, provide a link to the Creative Commons license, and indicate if changes were made.
} 


\section{INTRODUCTION}

The increasing resistance of microorganisms to antimicrobials is posing the greatest threat to human health and is also most challenging task to tackle it ${ }^{1}$. Beta-lactam antibiotics are the one which are most frequently prescribed drug to treat any bacterial infections ${ }^{2}$. Increasing resistance to antimicrobial agents is a major burden. Decreasing susceptibility to third generation cephalosporins among microorganisms is a matter of major concern. Production of $\beta$-lactamases enzyme in both gram positive and gram negative bacteria is the common cause for resistance to beta lactam antibiotics ${ }^{3,4}$. The main reason for increase in $\beta$-lactamases enzyme in bacteria is its widespread use and persistent exposure of $\beta$-lactam antibiotics which led to increase their spectrum of activity to include third generation cephalosporins and aztreonam. This is the reason for mutations in these enzymes and are called extended spectrum $\beta$-lactamases (ESBLS) ${ }^{5}$. In the mid 1980s, ESBL was first reported in Western Europe followed by US in the late $1980 s^{6}$. ESBLs are enzymes that inactivate third generation cephalosporins and monobactam. However, they remain sensitive to cephamycins and carbapenems. Resistance can be overcome by using beta lactamase inhibitors (clavulanic acid, sulbactam and tazobactam) in combination with $\beta$-lactam (amoxicillin, piperacillin) ${ }^{7}$. ESBL are classified under Bush's functional class $2 \mathrm{be}$. These enzymes are plasmid-mediated and are derived from point mutation of TEM on SHV $\beta$-lactamases ${ }^{8}$. Detection of ESBL producers and other acquired resistance mechanisms to beta-lactam antibiotics by phenotypic methods are very important to prevent spread to other patients in hospitals by implementing isolation procedures ${ }^{9}$. Recently, isolates from community acquired infections are reported more commonly than isolates from hospital acquired infections ${ }^{10}$. ESBLs have been found mainly in Enterobacteriacae like Klebsiella spp. and Escherichia coli, but have also been reported in Non-fermenters (Pseudomonas spp. and Acinetobacter spp.). ESBL-producing bacteria cause infections involving both immunocompetent and immunocompromised patients. But it is very difficult to treat these infections in immunocompromised patients where only limited options are left ${ }^{11}$. The increasing prevalence of $\beta$-lactamases producing bacteria not only reduces the treatment options but also increases the duration of hospital stay, morbidity and mortality. Hence, its detection by different methods is essential ${ }^{12}$. Microbiology laboratory should detect these enzymes and also their antibiotic susceptibility pattern to provide reliable treatment options to clinicians for treating patients.

As the burden of ESBL producing organisms is increasing, it becomes necessary to detect ESBL producers to formulate and implement antibiotic policy in all hospitals. Microbiological surveillance to know the prevalence and the type of $\beta$-lactamases helps to form effective antibiotic policy. Also, awareness regarding these enzymes among clinicians plays a major role for better patient care. The study was done to detect ESBL producer in Gram negative isolates from clinical samples and to know the antibiotic susceptibility pattern of these isolates.

\section{MATERIALS AND METHODS}

Retrospective study of 1 year duration from July 2018 to June 2019 was conducted at Chamarajanagar Institute of Medical Sciences. All Gram negative isolates from different samples were included. Socio-demographic details and culture and susceptibility results were collected from Microbiology Laboratory registers. Following standard procedures culture of samples, its identification and antibiotic susceptibility testing (AST) was done ${ }^{13}$. Kirby- Bauer disc diffusion method was used for AST following Clinical and Laboratory Standard Institute (CLSI) guidelines ${ }^{14}$.

The following antibiotics were tested: ampicillin $(10 \mu \mathrm{g})$, amoxiclav $(20 / 10 \mu \mathrm{g})$, gentamicin $(10 \mu \mathrm{g})$, amikacin $(30 \mu \mathrm{g})$, ciprofloxacin $(10 \mu \mathrm{g})$, cotrimoxazole $(1.25 / 23.75 \mu \mathrm{g})$, cefoxitin $(30 \mu \mathrm{g})$, cefepime $(30 \mu \mathrm{g})$, imipenem $(30 \mu \mathrm{g})$, piperacillintazobactam (100/10 $\mathrm{gg})$. Resistance data were interpreted according to CLSI guidelines $\left(29^{\text {th }} \mathrm{ed}\right.$. CLSI Supplement M100, 2019).

\section{Detection of ESBL}

\section{Phenotypic confirmatory test}

ESBL was detected by combination disk test using ceftazidime $(30 \mu \mathrm{g})$ alone and in combination with clavulanic acid (30 $\mu \mathrm{g} / 10 \mu \mathrm{g})$. $0.5 \mathrm{Mc}-F a r l a n d$ opacity of test organisms were inoculated into Mueller-Hinton agar (MHA) as lawn culture. The ceftazidime (CAZ) discs alone 
and in combination with clavulanic acid (CAC) were placed on MHA. Isolates showing increase of $\geq 5 \mathrm{~mm}$ in zone of inhibition of CAC discs in comparison to the $C A Z$ disc alone was considered to be ESBL producer.

\section{Data analysis}

\section{Ethical considerations}

Data analysis was done using MS Excel.

Ethical clearance was obtained from the Institutional Ethical clearance committee of Chamarajanagar Institute of medical sciences, Chamarajanagar.

Table 1. Organisms isolated from various samples

\begin{tabular}{|c|c|c|}
\hline Organisms & $\begin{array}{l}\text { Total isolates } \\
\text { No. (\%) }\end{array}$ & $\begin{array}{c}\text { ESBL producers } \\
\text { No. }(\%)\end{array}$ \\
\hline Escherichia coli & $176(33.8)$ & $121(23.2)$ \\
\hline $\begin{array}{l}\text { Klebsiella } \\
\text { pneumoniae }\end{array}$ & $58(11.1)$ & $32(06.1)$ \\
\hline Proteus spp. & $32(06.1)$ & $13(02.5)$ \\
\hline Citrobacter spp. & $49(09.4)$ & $24(04.6)$ \\
\hline Enterobacter spp. & $63(12.1)$ & $46(08.8)$ \\
\hline Acinetobacter spp. & $28(05.4)$ & $14(02.7)$ \\
\hline $\begin{array}{l}\text { Pseudomonas } \\
\text { aeruginosa }\end{array}$ & $115(22.1)$ & $79(15.2)$ \\
\hline Total & $521(100)$ & $329(63.1)$ \\
\hline
\end{tabular}

\section{RESULTS}

A total of 521 Gram negative isolates were isolated which included E. coli, Klebsiella pneumoniae, Citrobacter spp., Enterobacter spp., Proteus spp., and Acinetobacter spp. Pseudomonas aeruginosa as shown in Table 1 . Table 2 shows, of 521 isolates tested, 329 (63.1\%) were found to be ESBL producers. These ESBL producing isolates showed maximum susceptibility to piperacillintazobactam (86\%) followed by imipenem (78.4\%), amikacin $(63.5 \%)$, cotrimoxazole (54.4\%), ciprofloxacin (51\%), amoxi-clav (44.9\%), cefepime (44.1\%), gentamicin (38.9\%), cefoxitin (34.9\%) and ampicillin (19.1\%). as in Table 3.

\section{DISCUSSION}

The increasing prevalence of resistance is a major burden worldwide in antimicrobial therapy. Infections caused by these resistant organisms are responsible for treatment failure, prolonged illness and a risk of morbidity and mortality. Overuse and misuse of antimicrobial agents is the major concern for the development of

Table 2. Number of ESBL producers

\begin{tabular}{lc}
\hline $\begin{array}{l}\text { Total No. of Gram } \\
\text { negative isolates }\end{array}$ & $\begin{array}{c}\text { ESBL producers } \\
\text { No. (\%) }\end{array}$ \\
\hline 521 & $329(63.1)$
\end{tabular}

Table 3. Antibiotic susceptibility pattern of ESBL producers

\begin{tabular}{lllllllllll}
\hline Organisms & AMP & AMC & G & AK & CIP & COT & CN & CPM & MRP & PIT \\
\hline E. coli $(\mathrm{n}=121)$ & 46 & 71 & 58 & 82 & 85 & 94 & 57 & 49 & 98 & 109 \\
& $(14.0)$ & $(21.6)$ & $(17.6)$ & $(24.9)$ & $(25.8)$ & $(28.6)$ & $(17.3)$ & $(14.9)$ & $(29.8)$ & $(33.1)$ \\
Klebsiella pneumoniae & - & 13 & 11 & 23 & 17 & 19 & 15 & 19 & 25 & 21 \\
(n=32) & & $(3.9)$ & $(3.4)$ & $(6.9)$ & $(5.2)$ & $(5.8)$ & $(4.6)$ & $(5.8)$ & $(7.6)$ & $(6.4)$ \\
Proteus & 04 & 10 & 09 & 11 & 05 & 06 & 06 & 07 & 11 & 10 \\
spp. $(\mathrm{n}=13)$ & $(1.2)$ & $(3.0)$ & $(2.7)$ & $(3.4)$ & $(1.5)$ & $(1.8)$ & $(1.8)$ & $(2.1)$ & $(3.4)$ & $(3.0)$ \\
Citrobacter & - & 12 & 06 & 12 & 09 & 12 & 09 & 11 & 16 & 22 \\
spp. $(\mathrm{n}=24)$ & & $(3.7)$ & $(1.8)$ & $(3.7)$ & $(2.7)$ & $(3.7)$ & $(2.7)$ & $(3.4)$ & $(4.9)$ & $(6.7)$ \\
Enterobacter & 13 & 31 & 18 & 29 & 24 & 40 & 28 & 27 & 35 & 39 \\
spp. $(\mathrm{n}=46)$ & $(3.9)$ & $(9.4)$ & $(5.5)$ & $(8.8)$ & $(7.3)$ & $(12.1)$ & $(8.5)$ & $(8.2)$ & $(10.6)$ & $(11.9)$ \\
Acinetobacter spp. & - & - & 07 & 10 & 06 & 08 & - & 08 & 06 & 10 \\
(n=14) & & & $(2.1)$ & $(3.0)$ & $(1.8)$ & $(2.4)$ & & $(2.4)$ & $(1.8)$ & $(3.0)$ \\
Pseudomonas & - & - & 19 & 42 & 22 & - & - & 24 & 67 & 72 \\
aeruginosa $(\mathrm{n}=79)$ & & & $(5.8)$ & $(12.8)$ & $(6.7)$ & & & $(7.3)$ & $(20.3)$ & $(21.9)$ \\
Total $(\mathrm{n}=329)$ & 63 & 137 & 128 & 209 & 168 & 179 & 115 & 145 & 258 & 283 \\
& $(19.1)$ & $(41.6)$ & $(38.9)$ & $(63.5)$ & $(51.0)$ & $(54.4)$ & $(34.9)$ & $(44.1)$ & $(78.4)$ & $(86.0)$ \\
& & & & & & & & & &
\end{tabular}

AMP - Ampicillin, AMC - Amoxiclav, G - Gentamicin, AK - Amikacin, CIP - Ciprofloxacin, COT - Cotrimoxazole, CN - Cefoxitin, CPM - Cefepime, IMP - Imipenem, PIT - Piperacillin/Tazobactam 
acquired antimicrobial resistance. ${ }^{15}$ Production of Beta-lactamase enzyme (in both gram positive and gram negative bacteria) is the major mechanism for development of antimicrobial resistance. Although the prevalence of ESBL producer varies from country to country, it is more in Asia ${ }^{16}$. Although, ESBLs are commonly detected in members of Enterobacteriaceae especially E. coli and Klebsiella pneumoniae, other beta-lactamases like Amp C, MBL(Metallobetalactamases) are encountered in nonfermenters. Spread of betalactamases resistance between organisms is mainly due to plasmid mediated resistance. They also carry resistant genes to quinolones and aminoglycosides. These resistant strains are then spread in environment and transfer the genes coding for resistance to other bacteria ${ }^{15,17}$.

Our study showed prevalence of ESBL producer is $63.1 \%$ which was similar to studies done by Mathur et al. ${ }^{18}$ and Singhal et al. ${ }^{19}$ which showed positivity in $68 \%$ and $64 \%$ respectively. Among the members of Enterobacteriaceae, ESBL producers were maximum in E. coli, Enterobacter spp. and K. pneumonia which was similar to studies done by Mutasim E. et al. ${ }^{20}$ Among non-fermenters, Pseudomonas aeruginosa and Acinetobacter spp. exhibited ESBL production. E. coli and K. pneumoniae are the most common etiological agents of many infections. Irrational uses of antibiotics without following antimicrobial susceptibility report, uncontrolled sale of antibiotics over the counters without prescription are few factors which increases the spread of resistance. ESBLs are sensitive to carbapenems and cephamycins and resistance can be overcome by use of $\beta$-lactam along with $\beta$-lactamase inhibitors (sulbactam or clavulanic acid). Our study showed maximum susceptibility to piperacillintazobactam (86\%) followed by imipenem (78.4\%) and amikacin (63.5\%) which is similar to study done by Sangeetha K.T. et al. ${ }^{21}$ As observed in our study, Imipenem was effective among ESBL producers. Carbapenem should be considered as reserve drug and used only for infections caused for drug resistant organisms.

Creating awareness on antibiotic resistance of organisms, designing and effective implementation of antibiotic policy are few steps to be taken towards handling resistant organisms
(ESBL, MBL and AmpC producers) ${ }^{22,23}$. Regular microbiological surveillance is essential to know the prevalence of the these enzymes and their susceptibility pattern. Every hospital should have their own hospital antibiotic policy which is helpful for wise indications for antimicrobial choice. Following strictly the concept of "reserve drugs" and rational use of antibiotics will decrease the misuse of available antibiotics and also prevents further spread of drug resistance ${ }^{24}$. Treatment with combination therapy and use of new antibiotics may help against such drug-resistant organisms ${ }^{25}$. Implementation of antimicrobial stewardship program (AMSP) in a hospital provides strategies for rational use of antimicrobials. AMSP helps in use of right antimicrobial agent, for the right patient, at the right time, with the right dose, route and frequency, causing the least harm to the patients.

\section{CONCLUSION}

Multidrug-resistant ESBL producers are rapidly increasing and have become a burden. Detection of these enzymes in laboratory by simple disk method has to be routinely employed. Its detection and reporting will help in prescribing proper antibiotics, to understand the drug resistant patterns of ESBL producers and to prevent spread of these organisms and therapeutic failures.

\section{ACKNOWLEDGMENTS}

None.

\section{CONFLICT OF INTEREST}

The authors declare that there is no conflict of interest.

\section{FUNDING}

None.

\section{AUTHORS' CONTRIBUTION}

MDW drafted the manuscript, compiled data and designed tables. JS and PC collected data. SJV supervised and reviewed the manuscript.

\section{ETHICS STATEMENT}

This article does not contain any studies with human participants or animals performed by any of the authors. 


\section{DATA AVAILABILITY}

All datasets generated or analyzed during this study are included in the manuscript.

\section{REFERENCES}

1. Khan MN, Srivastava P, Chophi V, Nirwan PS. Prevalence of ESBL and AmpC $\beta$-Lactamase in Gram Negative Bacilli in various Clinical Samples at Tertiary Care Hospital. International Research Journal of Medical Sciences. 2015;3(8):1-6.

2. Baguma A, Atek K, Joel B. Prevalence of ExtendedSpectrum Beta-Lactamases Producing Microorganisms in Patients Admitted at KRRH, Southwestern Uganda. International Journal of Microbiology. 2017;2017:1-5. doi: 10.1155/2017/3183076

3. Rugved Kulkarni, Vaishali Dohe, Dnyaneshwari Ghadge, Arvind Bhore. A study of extended spectrum betalactamase (ESBL) producers in clinical isolates. Medical Journal of Western India. 2013;41(1):18-22.

4. Vatkar VS, Shadija PG, Ghosh SJ. Prevalence of ESBL Producers in Family Enterobacteriaceae Isolated from D. Y. Patil Medical College \& Hospital, Kolhapur. Journal of Evolution of Medical and Dental Sciences. 2015;4(70):12241-12245. doi: 10.14260/ jemds/2015/1764

5. Dalela G. Prevalence of Extended Spectrum BetaLactamase (ESBL) Producers among Gram Negative Bacilli from Various Clinical Isolates in a Tertiary Care Hospital at Jhalawar, Rajasthan. J Clin Diagn Res. 2012;6(2):182-187.

6. Metri BC, Jyothi P, Peerapur BV. The Prevalence of ESBL among Enterobacteriaceae in a Tertiary Care Hospital of North Karnataka, India. J Clin Diagn Res. 2011;5(3):470-475.

7. Sreekanth B, Dattaraya GS. Detection of extended spectrum $\beta$-lactamases (ESBLs) in clinical isolates. Int J Med Sci Public Health. 2014;3(9):1132-1134. doi: 10.5455/ijmsph.2014.010720142

8. Gupta S, Maheshwari V. Prevalence of ESBLs among Enterobacteriaceae and their Antibiotic Resistance Pattern from Various Clinical Samples. Int J Curr Microbiol Appl Sci. 2017;6(9):2620-2628. doi: 10.20546/ijcmas.2017.609.323

9. Drieux L, Brossier F, Sougakoff W, Jarlier V. Phenotypic detection of extended-spectrum $\beta$-lactamase production in Enterobacteriaceae: review and bench guide. Clinical Microbiology and Infectious Diseases. 2008;14(s1):90-103. doi: 10.1111/j.14690691.2007.01846.x

10. Prabha R, Joshy M. Easow, Swapna, M. Phenotypic detection of Extended Spectrum Beta- Lactamase producing uropathogens using DDST, PCT, Chrom agar and E-test - A comparitive study. Int J Curr Microbiol App/ Sci. 2016;5(4):565-577. doi: 10.20546/ ijcmas.2016.504.064

11. Raymond GB, Samer FS, Abdullah MS. Extended Spectrum $\beta$-Lactamases among Gram-Negative Bacterial Isolates from Clinical Specimens in Three Major Hospitals in Northern Jordan. International
Journal of Microbiology. 2009;2009:1-8. doi: $10.1155 / 2009 / 513874$

12. Khan MKR, Thukral SS, Gaind R. Evaluation of a modified double-disc Synergy test for detection of extended spectrum of $\beta$-lactamases in AmpC $\beta$-lactamase producing Proteus Mirabilis. Indian J Med Microbiol. 2008;26(1):58-61. doi: 10.4103/02550857.38860

13. Collee JG, Marmion BP, Fraser AG, Simmons A. Mackie and McCartney Practical Medical Microbiology, $14^{\text {th }}$ ed. Edinburgh: Churchill Livingstone.

14. Clinical Laboratory Standards Institutes (CLSI). Performance Standards for antimicrobial susceptibility testing. 29 $9^{\text {th }}$ ed. CLSI Supplement M100. Wayne, Pennsylvania, USA: National Committee for Clinical Laboratory Standards 2019.

15. JoseLR. Detection of ESBL Organisms in body fluids, a study from a tertiary care center. IOSR Journal of Dental and Medical Sciences (IOSR-JDMS). 2017;16(8):48-51.

16. Saxena A, Singh S, Goyal R, Saxena S. Antibiotic susceptibility pattern of extended spectrum $\beta$-lactamase ESBL producing gram negative bacilli in a tertiary care teaching hospital, Bareilly, India. Int J Basic Clin Pharmacol. 2019;8:228-33. doi: 10.18203/23192003.ijbcp20190139

17. Kolhapure RM, Kumar A, Rajkumar HRV. Coexpression of ESBL, Amp C and MBL in gram negative bacilli. J Res Med Sci. 2015;3:2698-703.

18. Mathur P, Kapil A, Das B, Dhawan B. Prevalence of extended spectrum $\beta$-lactamase producing gram negative bacteria in a tertiary care hospital. Indian $J$ Med Res. 2002; 115:153-57.

19. Singhal S, Mathur T, Khan S, et al. Evaluation of the methods for AmpC $\beta$-lactamase in gram negative clinical isolates from tertiary care hospitals. Indian J Med Microbiol. 2005;23(2):120-24. doi: 10.4103/02550857.16053

20. Ibrahim ME, Abbas M, Al-Shahrai AM, Elamin BK. Phenotypic Characterization and Antibiotic Resistance Patterns of Extended-Spectrum $\beta$-Lactamase- and AmpC $\beta$-Lactamase-Producing Gram-Negative Bacteria in a Referral Hospital, Saudi Arabia. Canadian Journal of Infectious Diseases and Medical Microbiology. 2019;2019:1-9. doi: 10.1155/2019/6054694

21. Sangeetha KT, Hittinahalli V, Lyra PR. Study on Phenotypic Detection of ESBL in Gram Negative Bacterial Isolates in a Tertiary Care Hospital in Bangalore. Int J Microbiol Res. 2018;10(3):1049-1051. doi: 10.9735/0975-5276.10.3.1049-1051

22. Phamba SG, Dominic RMS. Prevalence of Extended spectrum beta- lactamase (ESBL) producing Klebsiella species and Escherichia coli among clinical isolates in a tertiary care hospital. Journal of International Medicine and Dentistry. 2017;4(1):06-12.

23. Foad MF. Phenotypic Detection and Antimicrobial susceptibility Profile of ESBL, AmpC and Carbapenemase producing Gram-negative isolates from Outpatient clinic specimens. Int J Curr Microbiol Appl Sci. 2016;5(1):740-752. doi: 10.20546/ ijcmas.2016.501.075 
24. Patel J, Bhatt J, Javiya V, Patel K. Anti-Microbia Susceptibility Patterns of Enterobacteriaceae Isolated From A Tertiary Care Unit In Gujarat. The Internet Journal of Microbiology. 2008;6(1):1-8. doi: 10.5580/ b2b
25. Kazemian $\mathrm{H}$, Heidari $\mathrm{H}$, Ghanavati R, et al. Phenotypic and Genotypic Characterization of ESBL-, AmpC-, and Carbapenemase-Producing Klebsiella pneumoniae and Escherichia coli Isolates. Medical Principles and Practice. 2019;28:547-551. doi: 10.1159/000500311 